\title{
FEMINISMO 2.0: A MOBILIZAÇÃO DAS MULHERES NO BRASIL CONTRA O ASSÉDIO SEXUAL ATRAVÉS DAS MÍDIAS SOCIAIS (\#PRIMEIROASSEDIO)
}

\author{
Rose Marie Santini \\ Professora da Escola de Comunicação da Universidade Federal do Rio de Janeiro (ECO-UFRJ). Professora do \\ Programa de Pós-Graduação em Ciência da Informação do convênio IBICT-ECO/UFRJ e do Programa de Pós- \\ Graduação em Tecnologias e Linguagens da Comunicação da ECO-UFRJ. Email: marie.santini @eco.ufrj.br
}

\section{Camyla Terra}

Bacharel em Publicidade e Propaganda pela Escola de Comunicação da Universidade Federal do Rio de Janeiro. Email: terracamyla@gmail.com

\section{Alda Rosana Duarte de Almeida}

Professora da Escola de Comunicação da Universidade Federal do Rio de Janeiro (ECO-UFRJ). Professora do Programa de Pós-Graduação em Tecnologias e Linguagens da Comunicação da ECO-UFRJ. Email: alda.almeida@eco.ufrj.br

\begin{abstract}
Resumo
Muito vem se discutindo sobre igualdade de gênero e garantia de direitos para as mulheres em todo o mundo, mas o ano de 2015 foi decisivo para a construção de uma nova narrativa sobre os movimentos feministas na mídia, especialmente no Brasil. Esse ano é marcado por dois fatos sociais importantes. Por um lado, destaca-se a divulgação do "Mapa da Violência" de 2012 a 2015, que revelou dados atuais e inéditos sobre a realidade do feminicídio no nosso país. Por outro, iniciativas online questionaram tabus femininos que há décadas são pouco debatidos publicamente no Brasil pelos cidadãos e cidadãs comuns. Diante desse cenário, o objetivo desta pesquisa foi investigar a nova dinâmica dos movimentos sociais na chamada sociedade em rede a partir da mobilização das mulheres brasileiras nas redes sociais, onde o alcance das mensagens extrapola os domínios da vida social e cotidiana dos indivíduos diretamente envolvidos para infinitas redes de informação online. Para tal, foi realizado o estudo de caso da hashtag \#primeiroassedio através dos dados extraídos da rede social Twitter relacionados à campanha online ocorrida no Brasil em 2015, que foram interpretados e discutidos à luz da literatura sobre Análise de Redes Sociais (ARS ou SNA - Social Network Analysis). Os resultados encontrados indicam que a nova dinâmica dos movimentos sociais em redes online permite que um perfil com pouca ou nenhuma visibilidade midiática aparente, como o @ thinkolga, pode criar uma campanha de ação política e obter grande repercussão entre os usuários destas redes. Este novo fenômeno social pode apontar para uma possível atualização da tradicional teoria da espiral do silêncio na medida em que considera o efeito mútuo dos meios de comunicação de massa e das mídias sociais na formação da opinião pública.
\end{abstract}

\section{Palavras-chave}

Movimentos sociais. Feminismo 2.0. Redes sociais online. \#primeiroassedio. Twitter.

\section{FEMINISM 2.0: MOBILIZING WOMEN IN BRAZIL AGAINST SEXUAL HARASSMENT THROUGH THE MEDIA SOCIAL TOOLS (\#FIRSTHARASSMENT)}

\begin{abstract}
Much has been discussed on gender equality and guarantee of rights for women around the world, but the year 2015 was decisive for the construction of a new narrative about the feminist movement thought the media, especially in Brazil. This year is marked by two important social facts. First, we would like to stress the publication of "Map of Violence" from 2012 to 2015 that revealed current and new data on the reality of
\end{abstract}


femicide in our country. On the other, online initiatives questioned female taboos that are little publicly and debated in Brazil by ordinary citizens for decades. In this scenario, the aim of this research was to investigate the new dynamics of social movements in the so-called network society from the mobilization of Brazilian women in social networks, where the range of messages goes beyond the realms of social and everyday life of individuals directly involved to the endless of online information networks. To this end, we studied the case of \#primeiroassedio hashtag through data related to this campaign that took place in Brazil in 2015, taken from the online social network Twitter. This data extracted were interpreted and discussed in the light of the literature on Social Network Analysis (SNA). The results indicate that the new dynamics of social movements in online networks allows that a profile with little or no apparent media visibility, as @ thinkolga, to create a political action campaign and get great impact among users of these networks. This new social phenomenon may point to a possible update of the traditional theory of Spiral of Silence since it considers the mutual effect of the mass media and social media in shaping public opinion.

\section{Keywords}

Social Movements. Social Media. Feminism 2.0. Brazil. Twitter.

\section{INTRODUÇÃO}

Protestos nas ruas e mobilizações nas redes apontam novas tendências para a história dos movimentos sociais. O feminismo 2.0, uma nova geração de feministas que utilizam a internet como plataforma de luta, provoca novos debates nas redes sociais e ganha espaço a cada dia.

A realidade da violência contra a mulher no Brasil é o ponto de partida para reforçar a urgência do movimento feminista no país. Os resultados encontrados nos dados nacionais publicados nos relatórios do "Mapa da Violência" de 2012 e $2015^{1}$ revelam o feminicídio silenciado que ocorre no país hoje, apontando o Brasil como o quinto país que mais mata mulheres (WAISELFISZ, 2015). Esse relatório destaca ainda que em 71,9\% dos casos de violência contra a mulher acontecem na residência da vítima, e em grande maioria os agressores são integrantes do seu ciclo familiar.

A discussão da violação dos direitos das mulheres no Brasil ganhou fôlego em outubro de 2015 com o caso de assédio da Valentina, de 12 anos, participante do reality show culinário Masterchef, exibido pela Rede Bandeirantes. Dezenas de comentários de apologia ao estupro levaram o nome dela ao topo dos "Trending Topics" no Twitter. Mobilizados com a repercussão do caso, o projeto feminista Think Olga, criado em abril de 2013 pela jornalista Juliana de Faria e que tem como missão empoderar mulheres por meio da informação e

\footnotetext{
${ }^{1}$ O "Mapa da Violência" é um relatório produzido desde 1998 pela Área de Estudos sobre Violência da FLACSO Faculdade Latino-Americana de Ciências Sociais - que publica anualmente um documento que reuni informações para subsidiar discussão sobre as condições de garantia dos direitos humanos na América Latina. Em 2012 e 2015, pela primeira vez, a FLACSO dedicou um caderno complementar aos estudos sobre a violência contra mulheres e divulgou dados sobre "Homicídio de mulheres no Brasil".
} 
retratar as ações delas em locais onde a voz dominante não seja a mulher, lançou a campanha online \#primeiroassedio. A ação começou no dia 20 de outubro de 2015 no Twitter, com a seguinte mensagem: "Por favor, compartilhem suas histórias com a hashtag \#PrimeiroAssedio. Vamos reunir as histórias e publicá-las na OLGA” (THINK OLGA, 2015).

No quarto dia de atuação, a hashtag já alcançava 82 mil tweets, revelando a relevância do assunto. Uma análise feita pelo coletivo apontava 3.111 (três mil cento e onze) eram mensagens que denunciavam experiências de assédio sexual, e a idade média das vítimas, quando assediadas, era de 9,7 anos (THINK OLGA, 2015).

A grande repercussão da hashtag apontou que na maioria dos casos as vítimas são silenciadas e evidenciou a urgência de se abrir o debate sobre a violência e assédio sofridos pelas mulheres. Segundo as idealizadoras do Think Olga (THINK OLGA, 2015), a intenção era encorajar mulheres vítimas de qualquer tipo de assédio a quebrarem esse silêncio e denunciarem o que aconteceu com elas, mostrando que não estavam sozinhas e que não devem se sentir culpada pelo o que aconteceu.

Diante dessa campanha, somado a motivação pela onda de protestos observados desde a "primavera árabe" em 2011 e os movimentos sociais surgidos depois desse episódio - como o "Los Indignados" na Espanha, o "Occupy Wall Street" nos EUA e "Junho de 2013" no Brasil - surge o desejo de transformar essa realidade. Assim, o objetivo nessa pesquisa foi investigar a nova dinâmica dos movimentos sociais na chamada sociedade em rede, onde o alcance dos meios de comunicação extrapola para todos os domínios da vida social e cotidiana em infinitas redes de informação. Para tal, foi analisado o estudo de caso da hashtag \#primeiroassedio.

\section{A FORMAÇÃO DA OPINIÃO PÚBLICA EM UMA SOCIEDADE EM REDE}

De certa maneira a eficácia dos movimentos sociais depende de sua repercussão e apoio no âmbito da esfera pública. Sobre este aspecto, diferentes teorias das ciências sociais discutem o efeito dos meios de comunicação na formação da opinião pública, especialmente o papel destes meios na construção de uma opinião dominante. Entretanto, é preciso revisitar tais diagnósticos e teorias diante das novas circunstâncias tecnológicas, sociais, culturais e políticas dos meios de comunicação e suas audiências na chamada sociedade em rede.

Na gênese da formação da opinião pública, segundo a Teoria da Espiral do Silêncio de Elizabeth Noelle-Nuemann (2005), é frequente a polarização da opinião em diferentes grupos que se diferenciam quanto a sua visibilidade discursiva. A autora destaca que há dois grupos de pessoas que, mesmo se sentindo minoria, nunca são silenciadas. O primeiro seria o "núcleo 
duro", composto pelas pessoas que já expressaram sua opinião sobre determinado assunto, sofreram retaliação e por isso não têm nada a perder por falar. Esses entendem o isolamento como um preço a se pagar por expressar opiniões divergentes. O outro grupo seria o de vanguardistas, intelectuais, artistas e "transformadores sociais" que tendem a construir novas ideias. Os indivíduos desse último costumam ser comprometidos com o futuro, e por necessidade estão isolados, mas a convicção de que eles estão à frente de seu tempo lhes permite suportar a ideia do isolamento.

Uma oportunidade para que haja possíveis oscilações no sentimento coletivo da opinião dominante, e por consequência a quebra de uma determinada condição de "espiral do silêncio" seria a intervenção feita por pessoas pertencentes a um destes dois grupos. Isso porque elas não têm medo de serem impopulares nem isolados.

Porém, atualmente surge uma ferramenta sócio-técnica de comunicação e novos usos sociais que modifica a teoria e permite a quebra da "espiral do silêncio": o uso das redes sociais online como espaços públicos para se discutir assuntos pessoais. Se considerarmos essas redes como um ambiente de "micro-clima", onde pessoas conhecidas entre si trocam informações, é possível enxergá-lo como um espaço de intervenção na "espiral do silêncio". Isso porque a pressão social da opinião dominante é exercida em espaços formais ou semiformais, e as redes sociais configuram um espaço potencialmente informal e horizontal de discussão.

Dessa forma, a iniciativa do coletivo Think Olga é um exemplo de quebra da espiral do silêncio das vítimas de assédio sexual, usuárias da rede social Twitter. Porém, é preciso analisar em que momento a ação do coletivo ganhou relevância na rede para fazer essa quebra. A esperança deste rompimento dependeria não só de um grupo que resista a pressão do isolamento ou de uma ferramenta digital propícia, mas principalmente de uma figura ou um acontecimento que dê relevância a voz dessa minoria para disputar o espaço discursivo com diferentes formadores da opinião pública.

Segundo Noelle-Nuemann (2005), quando um indivíduo silenciado encontra "parceiros verdadeiros" que compartilham de sua experiência ou de sua opinião, são capazes de resistir à pressão do grupo e escapar do medo do isolamento. Diante do objeto estudado, essa possibilidade da quebra do silêncio seria, portanto, impulsionada pelos "parceiros verdadeiros" que relataram seus casos de primeiro assedio nas mensagens que receberam a tag \#primeiroassedio. Nesse caso, a unidade criada pela hashtag teria colaborado para o sentimento de pertencimento das vítimas. Esta rede de "parceiros verdadeiros" teria desencadeado uma viralização da hashtag e a quebra do silêncio de milhares de usuários 
vítimas de assédio.

\title{
2.1 A nova dinâmica dos movimentos sociais em rede: o Feminismo 2.0
}

O termo "movimento social" vem sendo utilizado para definir diversas manifestações sociais e culturais nas últimas décadas. O sociólogo francês Alain Touraine (2006), por exemplo, alerta sobre a aplicabilidade do termo na atual sociedade, sendo necessário distinguir claramente, em cada tipo de sociedade, os movimentos sociais propriamente ditos e reservar a ideia do termo a uma ação coletiva que coloque em questão um modo de dominação social generalizada. Na era das redes sociais na internet, é interessante refletir quais seriam as novas fronteiras dos movimentos sociais. Ou seja, campanhas nas redes sociais, petições online, iniciativas hackers ou os chamados "twitaços" seriam parte dos novos movimentos sociais?

Touraine (2006) questiona se é possível falar em "movimento social” em sociedades pós-industriais às quais muitos observadores chamam sociedade da informação ou da comunicação. Logo em seguida o sociólogo responde à própria pergunta:

\begin{abstract}
não há qualquer razão para não aplicarmos a esse novo tipo societal a análise que usamos para outras sociedades. Não é difícil ver, em diversos países e em tipos de sociedades muito diferentes, conflitos tocando a apropriação da informação e do conhecimento. Estudos sobre mídias foram realizados em hospitais, em escolas para mostrar a existência de conflitos fundamentais concernentes à utilização social da informação. Não há razão de dispensar o conceito de movimento social, recusando utilizá-lo em tipos de sociedade cada vez mais claramente separadas das sociedades industriais (TOURAINE, 2006, p.22).
\end{abstract}

Nesse sentido, seria possível compreender uma ação online coletiva - que tenha como característica o ímpeto de transformação no âmbito social e não unicamente histórico - como parte ou o próprio movimento social. Por esse ângulo, seria aplicável o termo "movimento social" em ações coletivas na Internet que marcam o recente revigoramento do movimento feminista.

O movimento que ganhou força em 2015 e ficou conhecido como "movimento das mulheres" ou "primavera das mulheres" luta, através de ações online, para que os direitos das mulheres sejam respeitados. Um exemplo deste fenômeno foi a campanha \#primeiroassedio ocorrida no Brasil através das redes sociais online, que mobilizaram centenas de milhares de pessoas e abriram novos debates sobre o tema, caracterizando-se assim como um movimento social em rede.

Isso porque as redes sociais online são um importante espaço de disputa de fala na sociedade atual e a pluralização de narrativas é um poderoso instrumento de transformação. 
Há um outro argumento de Touraine (2006) que aponta justamente para a importância de, ao falarmos de movimento social, privilegiar o ponto de vista dos atores - isto é, dos atores que são, ao mesmo tempo, conscientes do que têm em comum e dos mecanismos de conflitos e dos interesses particulares que os definem uns contra os outros.

Porém, ainda que se aplique o termo "movimento social" em ações coletivas nas chamadas sociedades pós-industriais, é preciso reconhecer uma mudança circunstancial fundamental em comparação com os movimentos sociais tradicionais. E para entender melhor tais mudanças, faz-se necessário analisar a dinâmica do fluxo de informação que caracteriza a sociedade em rede (CASTELLS, 2013).

Castells (2013) e diversos outros autores argumentam que a sociedade em rede surge após o aceleramento das transformações tecnológicas da comunicação na chamada Era da Informação. Tal paradigma social se caracteriza pelo alcance dos meios de comunicação para todos os domínios da vida social, numa rede que é simultaneamente global e local, genérica e personalizada, num padrão em constante mudança.

A mudança do ambiente comunicacional afetou, segundo Castells (2013), diretamente as normas de construção de significado e, portanto, a produção de relações de poder. Com isso, observa-se que o que o autor chama de "auto-comunicação de massa" fornece a plataforma tecnológica para a construção da autonomia do ator social, seja individual ou coletivo, em relação às instituições da sociedade.

A partir dessa perspectiva, pode-se acompanhar as análises feitas por Castells (2013) sobre a onda de revoltas iniciada pelos países árabes no final de 2010, que ficou conhecida como "Primavera Árabe" e que reverberou para outros lugares do mundo provocando movimentos espontâneos como "Los Indignados" na Espanha, "Occupy Wall Street", nos EUA, "Junho de 2013" no Brasil, entre outros. O autor trata desses acontecimentos como movimentos sociais típicos da sociedade em rede, fazendo uma análise quanto a sua formação, dinâmica, valores e perspectivas de transformação social. Segundo Castells (2013) há semelhanças fundamentais nestes casos: “os movimentos ignoraram partidos políticos, desconfiaram da mídia, não reconheceram nenhuma liderança e rejeitaram toda organização formal, sustentando-se na internet e em assembleias locais para o debate coletivo e a tomada de decisões" (CASTELLS, 2013, p. 12).

É interessante observar que a análise de Castells (2013) expõe a constituição de uma nova dinâmica dos movimentos sociais em uma sociedade em rede. Com a ampliação do alcance dos meios de comunicação para todos os domínios da vida social forma-se uma rede 
de informação que "empondera"² o ator social. Esse cenário se torna propício ao surgimento de ações coletivas espontâneas.

Ou seja, é possível dizer que o resgate do movimento feminista no mundo, inclusive a "Primavera das Mulheres" no Brasil, está ligado às experiências dos movimentos sociais analisados por Castells (2013). O Feminismo 2.0 seria, portanto, um dos efeitos das transformações vividas nesta sociedade em rede, porém relacionado especificamente a questão da inserção social das mulheres.

Similarmente, se dedicando a investigar questões como gênero, movimentos sociais e mídia digital, Crossley (2015) publicou o artigo "Facebook feminism: social media, blogs, and new technologies of contemporary feminism", que buscou desvendar como as redes sociais on-line e as relações de amizade podem moldar os movimentos sociais. A autora parte da premissa de que há uma relação muito próxima entre redes sociais e movimentos sociais e, em sua análise, teve algumas impressões iniciais que a fizeram acreditar que as relações interpessoais das redes sociais ajudavam a recrutar membros, sustentar organizações, nutrir a identidade dos participantes do movimento e difundir informação. Segundo Crossley (2015), os blogs feministas online são de extrema importância para o movimento porque é um espaço em que as mulheres são autoras e podem compartilhar seus pontos de vista, já que é difícil elas encontrarem suas perspectivas refletidas na grande mídia. Esses blogs seriam, sobretudo, um espaço para se informar sobre o movimento feminista.

Sobre o uso Facebook, os relatos das experiências expostos pela autora foram diferentes, pois ele funcionaria para expandir estruturas de mobilização e ampliar bases de recrutamento. Isso porque as ferramentas e algoritmos disponíveis no Facebook possibilitariam a unificação dos usuários a partir da identificação de uma causa feminista e facilitaria a circulação das perspectivas feministas para os seus amigos feministas e nãofeministas, usuários da rede. Essa possibilidade de recrutar membros de outros núcleos sociais seria uma forte colaboração do movimento on-line na atuação dos movimentos sociais offline. Diferentemente dos blogs feministas online, outro ponto sobre o uso do Facebook foi a forte polarização de opiniões nessa plataforma, onde diversas situações em que ocorreram discussões calorosas com algum amigo próximo ou familiar sobre questões feministas foram relatadas (CROSSLEY, 2015).

Assim, Crossley (2015) concluiu que os ativistas de blogs feministas na internet e da

\footnotetext{
${ }^{2}$ Este termo não existe em português, porém é utilizado para se referir ao significado de empowerment, em inglês que remete a "ganhar força ou poder de agir" de determinado ator social
} 
rede social Facebook expressam orgulho e entusiasmo em suas crenças e comunidades feministas, descobrindo ainda que o crescimento de consciência é crucial para motivar os participantes, ensinando aos potenciais participantes a ideologia do movimento em questão, e criando solidariedade entre eles. Esse argumento corrobora com a ideia de que ao fazer uma denúncia de violência contra a mulher, o crime deixa de ser invisível e se torna público, gerando empatia de outras mulheres que sofreram situações semelhantes ou daquelas que se identificam com a vítima em algum nível ou circunstância.

Os blogs feministas e o Facebook criam e sustentam a solidariedade entre os indivíduos mobilizados (CROSSLEY, 2015), mesmo que eles nunca tenham se encontrado pessoalmente. Neste sentido, o ativismo on-line possibilita reunir sujeitos distantes geograficamente, e os participantes espalham ideologias feministas em grandes redes de pessoas, impulsionando o movimento para além de conexões locais face-a-face. Essa possibilidade de incluir mais pessoas com diversidade geográfica no ativismo feminista é a superação de um velho desafio dos movimentos sociais.

A pesquisa sugere ainda que há uma dinâmica única do feminismo atuante no Facebook. Segundo Crossley (2015), as amizades na rede social Facebook são divididas em duas principais categorias: os laços fortes, que seriam responsáveis por cultivar o sentimento de comunidade e organizar ações coletivas; e os laços fracos, que criariam oportunidades para expandir bases de recrutamento e atingir um grande número de pessoas com as quais eles não entram em contato em suas vidas off-line. Portanto, Crossley (2015) atesta o terreno propício da internet para o nascimento de inquietações sociais.

\section{O ESTUdO DO CASO DA DISSEMINAÇÃO DA HASHTAG \#PRIMEIROASSÉDIO NAS REDES SOCIAIS}

A fim de compreender a atividade da campanha "\#primeiroassedio", extraiu-se os dados do uso da hashtag na rede social Twitter, a partir do software "Radian 6 Analysis Dashboard", entre o período de 20 de outubro a 07 de novembro de 2015. Após a extração, foram gerados grafos para visualização e análise da rede composta pelas atividades dos usuários em torno da hashtag estudada. A atividade da hashtag é medida pela quantidade de retweets que ela provoca na rede. É importante lembrar que, para a visualização das redes, a distância entre os pontos do grafo está relacionada com o grau de interação entre eles, ou a quantidade de retweets que recebeu. De acordo com a quantidade de menções que o usuário tem, ele ganha relevância na rede e visualmente o ponto que o representa fica maior. Quando 
há um aglomerado de pontos, apontando muitas ligações entre si, são chamados de cluster. Uma rede pode ter vários clusters e inclusive eles podem estar ligados entre si. O usuário (nó) que faz a ligação entre clusters é chamado de hub.

Foram registrados 44.537 tweets com a hashtag \#primeiroassedio no período da extração e eliminamos os tweets sem interação, deixando apenas a apresentação gráfica dos retweets, restando 32.734 tweets, total estudado nos grafos. O gráfico 1 representa a quantidade de retweets dia a dia sendo que o ápice da atividade da hashtag foi 22 de outubro de 2015, com 18.566 retweets. Com os dados extraídos, criou-se uma lista dos dez usuários mais retweetados, sendo que o primeiro, com 1.149 retweets, foi o @ ThinkOlga, como pode ser observado na tabela 1.

Gráfico 1: Quantidade de retweets por dia.

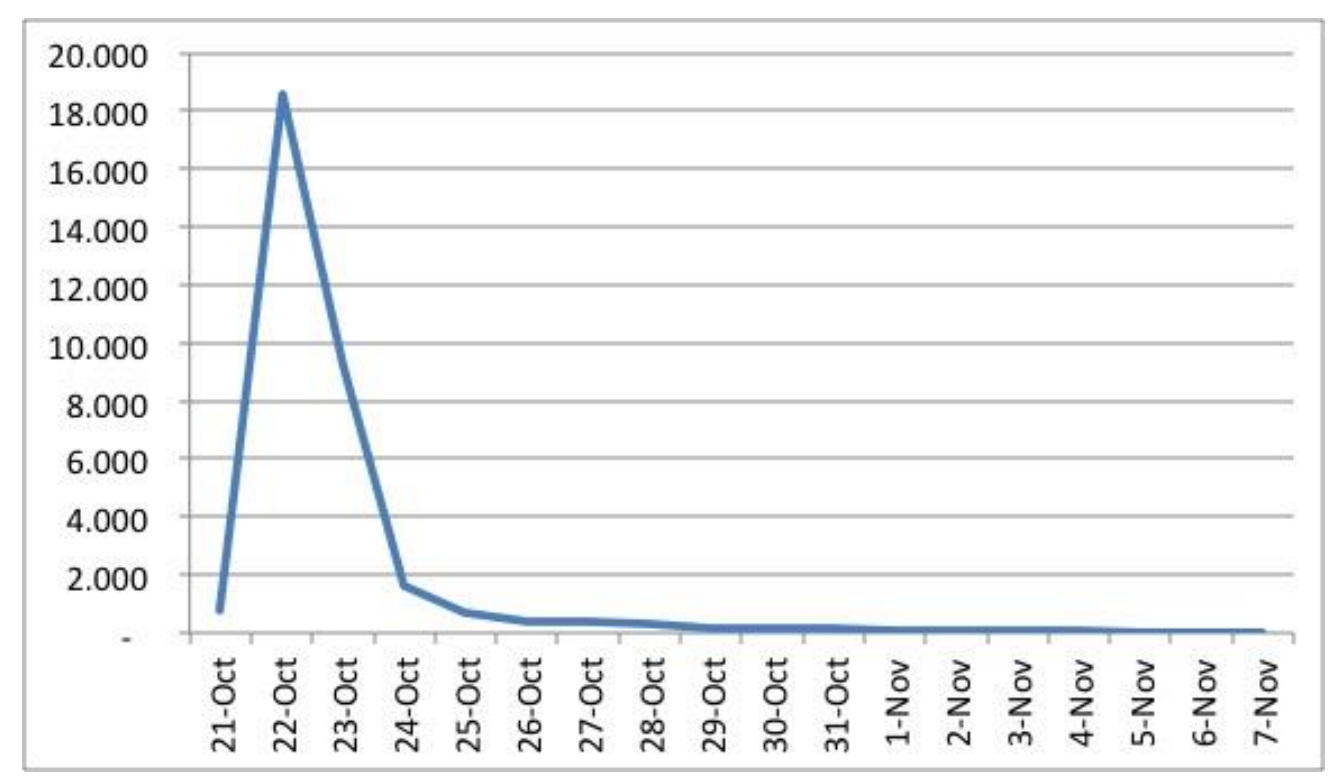

Fonte: As autoras (2015) 
Tabela 1: Os usuários mais retweetados.

\begin{tabular}{ccc}
\hline & Rowlabel & Total \\
\hline $\mathbf{1}$ & @ thinkolga & 1.149 \\
\hline $\mathbf{2}$ & @ roxmo & 1.066 \\
\hline $\mathbf{3}$ & @ yyasminleal & 1.032 \\
\hline $\mathbf{4}$ & @ marquerroni & 917 \\
\hline $\mathbf{5}$ & @ pridenian & 850 \\
\hline $\mathbf{6}$ & @ losthours & 663 \\
\hline $\mathbf{7}$ & @ glaubermacario & 564 \\
\hline $\mathbf{8}$ & @izzfigueiredo & 543 \\
\hline $\mathbf{9}$ & @ luhugerth & 539 \\
\hline $\mathbf{1 0}$ & @igornatusch & 533 \\
\hline
\end{tabular}

Fonte: As autoras (2015)

O segundo perfil com mais interação foi o @ roxmo, do músico brasileiro e vocalista da banda de rock Ultraje a Rigor, Roger Rocha Moreira, que tem 662 mil seguidores. O terceiro foi o@yyasminleal, que se auto descreve como "Estudante de jornalismo, feminista que prefere ir de vermelho a esquerda". Yasmin tem perfil de um usuário comum do Twitter, com 322 seguidores e nenhum vínculo midiático aparente.

Os perfis que mais retweetaram, ou seja, os que mais replicaram mensagens ou marcaram outros perfis foram os seguintes: @a_controlfreak (115), @luindarkness (83), @ demsgillet (67). Os três perfis indicados têm características de usuários comuns com alta participação online e nenhum vínculo midiático aparente.

O tweet que mais repercutiu, com 1.065 replicações, foi do perfil @ roxmo, no segundo dia, com a mensagem: “\#primeiroassedio Acho que eu tinha uns 10 anos. Uma empregada me deixou pegar nos peitos dela. Foi bom pra cacete" (MOREIRA, 2015). É interessante observar que o tweet mais retweetado possui conteúdo reacionário e representa a cultura dominante do machismo. Interpretado por muitos usuários como uma mensagem ofensiva e uma atitude de falta de respeito à luta feminista contra o assédio sexual,

Observou-se que campanha \#primeiroassedio teve a grande maioria de menções de apoio às vítimas e de mensagens de indignação com a vulnerabilidade sofrida pelas mulheres no Brasil. Ao surgir o tweet do @ roxmo (MOREIRA, 2015), muitos usuários retweetam repudiando sua posição, fazendo com que seu perfil ganhasse relevância. Essa reação corrobora com a ideia de forte polarização de opiniões presente nas redes sociais online, como foi identificado nos auto-relatos de Crossley (2015).

O segundo tweet mais replicado foi publicado pelo perfil @yyasminleal, com 887 retweets, no dia 22 de outubro, em que tweetou uma imagem com um mosaico de prints de 
tweets com mensagens publicadas no Twitter por usuários terceiros que fazem apologia à cultura do estupro, e complementou com a seguinte frase em tom de ironia: "não existe cultura do estupro" (LEAL, 2015). O terceiro tweet com mais replicações foi publicado por @ pridenian, no dia 23 de outubro, e em seu tweet há uma imagem com um texto sobre o assédio que as mulheres sofrem em situações diárias, acompanhada pela frase "Isso dói na alma" (RENAULT, 2015).

Até então, os top tweets coincidem com os perfis mais retweetados. Mas é curioso perceber que, apesar de @ thinkolga ser o perfil mais retweetado, segundo os dados extraídos, ele aparece na posição 15, pois teve muitos tweets com média repercussão. Nota-se, também, que os top tweets concentram-se no dia 22, justificando a variação significativa no gráfico 1 .

Para acompanhar a movimentação desses atores ao longo dos 19 dias de atividades na rede, capturados pela pesquisa, foram registrados cinco momentos da campanha onde pode-se observar a posição e a relevância dos usuários e dos retweets em grafos.

No grafo 1 (Apêndice 1), mostra que a rede ainda está tomando forma, com a relevância ainda bem dividida entre muitos usuários. É possível identificar vários possíveis clusters, sendo um deles, o perfil @ ThinkOlga. No grafo 2 (Apêndice 2), percebe-se que o perfil o @ roxmo cresce e novos perfis surgem. O usuário @igornatusch, que se autodescreve como jornalista e escritor e acumula 4.700 seguidores, aparece no grafo 2 com a cor verde. Ele ganha relevância depois da mensagem: "Debochar da hashtag \#primeiroassedio é tão pequeno, tosco e vulgar que desafia adequada descrição. Tem que ser BEM otário, em suma" (NATUSCH, 2015). No grafo 3 (Apêndice 3), que representa o marco central, observa-se uma tendência de maior centralização da rede sendo possível identificar os principais atores da hashtag em cena: @yyasminleal, @marquerroni, @thinkolga e @roxmo. O perfil @yyasminleal, já identificado como o terceiro mais retweetado, surge com muita relevância assim como@marquerroni, quarto perfil mais retweetado. O perfil @ thinkolga permanece sendo mencionado, mas perde o destaque, assim como @ roxmo. No grafo 4 (Apêndice 4), surge o @ pridenian, o quinto perfil mais replicado da rede. Os perfis @yyasminleal, @marquerroni, @thinkolga permanecem em cena sendo retweetados. Outro usuário que ganha relevância nesse momento da rede é @lucianagenro, a política de esquerda que coleciona 180 mil seguidores. O tweet dela recebeu 402 replicações com a mensagem: "Um cantor ignorante usou a \#PrimeiroAssedio p/ fazer piada sexual c/ a empregada. Se não estuda ao menos podia ver o "Que horas ela volta"' (GENRO, 2015). A mensagem é uma crítica ao tweet do Roger Moreira (2015) e faz referência ao filme brasileiro, que conta a história de uma empregada doméstica, que mora numa casa de família, e sua filha vai fazer uma visita a 
ela e acaba sendo assediada pelo patrão dela.

Houve uma falha operacional no grafo 4 e por isso não está determinado o perfil respectivo ao círculo rosa. Por dedução, seria o @roxmo, que é o autor da mensagem mais retweetada de toda a atividade e nesse mesmo momento é colocado em situação polêmica pelo tweet de @lucianagenro.É interessante observar que o perfil @ roxmo, é um hub, por ter sido o mais retweetado e receber maior atenção dos usuários, porém afastado da rede que começa a postar mensagens de apoio a campanha.

No grafo 5 (Apêndice 5), há cinco perfis em destaque. O @izzfigueiredo, é feminino e tem a maior relevância, com a mensagem: "E agora? A gente chora... \#primeiroassedio" (FIGUEIREDO, 2015), acompanhado de uma imagem contendo um depoimento que reproduz frases machistas ditas no dia a dia. Além desse perfil em destaque, permanecem com relevância@pridenian, @marquerroni, @thinkolga, @ roxmo e @yyasminleal e @lucianagenropulvinar.

\section{CONSIDERAÇÕES FINAIS}

$\mathrm{Na}$ era das redes sociais na internet, é interessante refletir quais seriam as novas fronteiras dos movimentos sociais. Ou seja, as campanhas, petições online, iniciativas hackers ou os chamados "twitaços" seriam parte dos novos movimentos sociais?

Segundo Touraine (2006), seria possível compreender uma ação online coletiva que tenha como característica o ímpeto de transformação no âmbito social - e não unicamente histórico - como sendo um movimento social. Por esse ângulo, seria aplicável o termo "movimento social" em ações coletivas como a campanha \#primeiroassedio, ocorrida no Brasil.

Similarmente, Castell (2013) expôs que a "sociedade em rede" proporciona a formação da "auto-comunicação de massa", uma rede de informação que "empondera" o ator social. Esse cenário se torna propício ao surgimento de ações coletivas espontâneas. Ou seja, é possível dizer que o resgate do movimento feminista no Brasil está ligado às experiências dos movimentos sociais analisados por Castells (2013) e o Feminismo 2.0 seria, portanto, um dos efeitos das transformações vividas nesta sociedade em rede, dando espaço a questão específica da inserção social das mulheres.

De forma mais específica, Crossley (2015) descobriu que o crescimento de consciência é crucial para motivar os participantes, ensinando aos potenciais ativistas a ideologia do movimento em questão, e criando solidariedade entre eles. Esse argumento 
corrobora com a ideia de que ao fazer uma denúncia de violência contra a mulher, o crime deixa de ser invisível e se torna público, gerando empatia de outras mulheres que sofreram situações semelhantes ou daquelas que se identificam com a vítima em algum nível ou circunstância. A redes sociais online criam e sustentam a solidariedade entre os indivíduos mobilizados mesmo que esses indivíduos nunca tenham se encontrado pessoalmente. Para Crossley (2015), há uma dinâmica única do feminismo atuante nas redes sociais online.

Assim, o estudo de caso da hashtag \#primeiroassedio, estudado aqui, ilustra essa nova dinâmica dos movimentos sociais em rede na internet que permitiu que um perfil com nenhuma exposição ou fama midiática aparente, como o @ thinkolga, criasse a campanha. Por outro lado, observa-se que a campanha ganha relevância na rede com o tweet do perfil @ roxmo.

A partir disso arriscamos argumentar que a estrutura das redes sociais online é propícia para que o ativismo feminista se organize, mas não garante sua relevância na rede. Vale ressaltar que Crossley (2015) defende que o ativismo online precisa combinar dois fatores numa rede: usuários com laços fortes, com afinidades e história comum no movimento feminista, responsáveis por cultivar o sentimento de comunidade e organizar ações coletivas na Internet; e usuários com laços fracos, que não pertence ao movimento feminista, mas contribuem com a causa ao disponibilizar suas próprias redes de conexões heterogêneas. Estes últimos possuem um importante papel na expansão das bases de recrutamento e divulgação das mensagens online, que passam a atingir um número maior de pessoas que não entrariam em contato com a causa feminista no mundo off-line.

A quebra da "espiral do silêncio" com a hashtag \#primeiroassedio só foi possível, portanto, pela união de um coletivo feminista pouco conhecido, porém com folego e sensibilidade para lançar uma campanha online que instigou todos os tipos de mulheres, e a interferência de um perfil com alto apelo midiático, que acabou provocando uma grande repercussão e tornou possível que o movimento se espalhasse amplamente na rede. Vale ressaltar que, sabendo que o movimento feminista luta pela narrativa histórica plural que contemple a visão de mundo das mulheres, dos nove atores de maior relevância na atividade da hashtag \#primeiroassedio no Twitter, sete são perfis femininos e apenas dois são masculinos, o que alerta para a hipótese de que haveria uma maior igualdade de gênero no ambiente digital.

Assim, esse caso aponta para uma agenda de pesquisa para os estudos feministas na mídia que considere a nova dinâmica dos movimentos sociais nas redes sociais online, ou sociedade em rede, uma vez que são plataformas que representam um importante espaço de 
disputa discursiva para as novas gerações e apresentam a possibilidade de pluralização das narrativas, um poderoso instrumento de transformação para a causa feminista. As novas mídias apresentam desafios para a renovação da luta social e do ativismo, que precisam criar soluções para ampliar os espaços de visibilidade e discussão sobre a violência contra a mulher, escapando assim do silenciamento das opiniões não-dominantes típico dos meios de comunicação de massa tradicionais no Brasil.

Entretanto, argumentamos que nem sempre as redes online poderão cumprir a função de facilitar a ação coletiva. Estas redes atuam em apenas uma, dentre as muitas camadas que compõem as estruturas sociais nas quais estamos inseridos. Significa dizer que, por um lado, não podemos prever a próxima onda de mobilização online através de uma análise das redes sociais online. Por outro, os usos destas redes podem funcionar como gatilho para o crescimento de um movimento qualquer, seja feminista, machista, por causas sociais ou racista. Porém, novas pesquisas empíricas neste campo fazem-se necessárias para fomentar a discussão sobre o papel das novas e velhas mídias na política contemporânea, para que possamos compreender as lógicas sociais emergentes do "feminismo 2.0" e seu potencial para a causa das mulheres no Brasil.

\section{REFERÊNCIAS}

CASTELLS, M. Redes de indignação e esperança. Movimentos sociais na era da internet. Rio de Janeiro: Zahar, 2013.

CROSSLEY, Alison. Facebook feminism: social media, blogs, and new technologies of contemporary u.s. feminism. Mobilization: An International Quarterly, v.20 (2): p. 253$268,2015$.

FIGUEIREDO, Isis. Twitter post. 23 out. 2015. Disponível em: <https://twitter.com/putzbel/status/657643189055193089>. Acesso em: 22 fev. 2016.

GENRO, Luciana. Twitter post. 23 out. 2015. Disponível em: <https://twitter.com/lucianagenro/status/657634387954110464>. Acesso em: 22 fev. 2016.

LEAL, Yasmin. Twitter post. 22 out. 2015. Disponível em:

<https://twitter.com/yyasminleal/status/657332260811710464>. Acesso em: 22 fev. 2016.

MOREIRA, Roger. Twitter post. 22 out. 2015. Disponível em: <https://twitter.com/roxmo/status/657254228411420674?lang=pt>. Acesso em: 22 fev. 2016.

NATUSCH, Igor. Twitter post. 22 out. 2015. Disponível em: <https://twitter.com/igornatusch/status/657277454499913728>. Acesso em: 22 fev. 2016. 
Communication Theory, 7 th Edition. EUA: McGran-Hill, 2005, p.372-382

RENAULT, Aline. Twitter post. 23 out. 2015. Disponível em:

<https://twitter.com/pridenian/status/657598674139262976>. Acesso em: 22 fev 2016.

THINK OLGA. Hashtag Transformação: 82 mil tweets sobre o \#PrimeiroAssedio. 26 de outubro de 2015. Disponível em: <http://thinkolga.com/2015/10/26/hashtag-transformacao82-mil-tweets-sobre-o-primeiroassedio/>. Acesso em: 02 mar. 2016.

TOURAINE, Alain. Na fronteira dos movimentos sociais. Sociedade e Estado, Brasília, v21. n. 1, p. 17-28, jan./abr, 2006.

WAISELFISZ Julio Jacobo. Mapa da Violência 2015: Homicídio de Mulheres no Brasil. Flacso Brasil. 2015. 9 Nov. 2015. Disponível em: <http://flacso.org.br/>. Acesso em: 28 fev. 2016

\section{APÊNDICES}

Apêndice 1: Grafo 1 - Primeiro momento da rede.

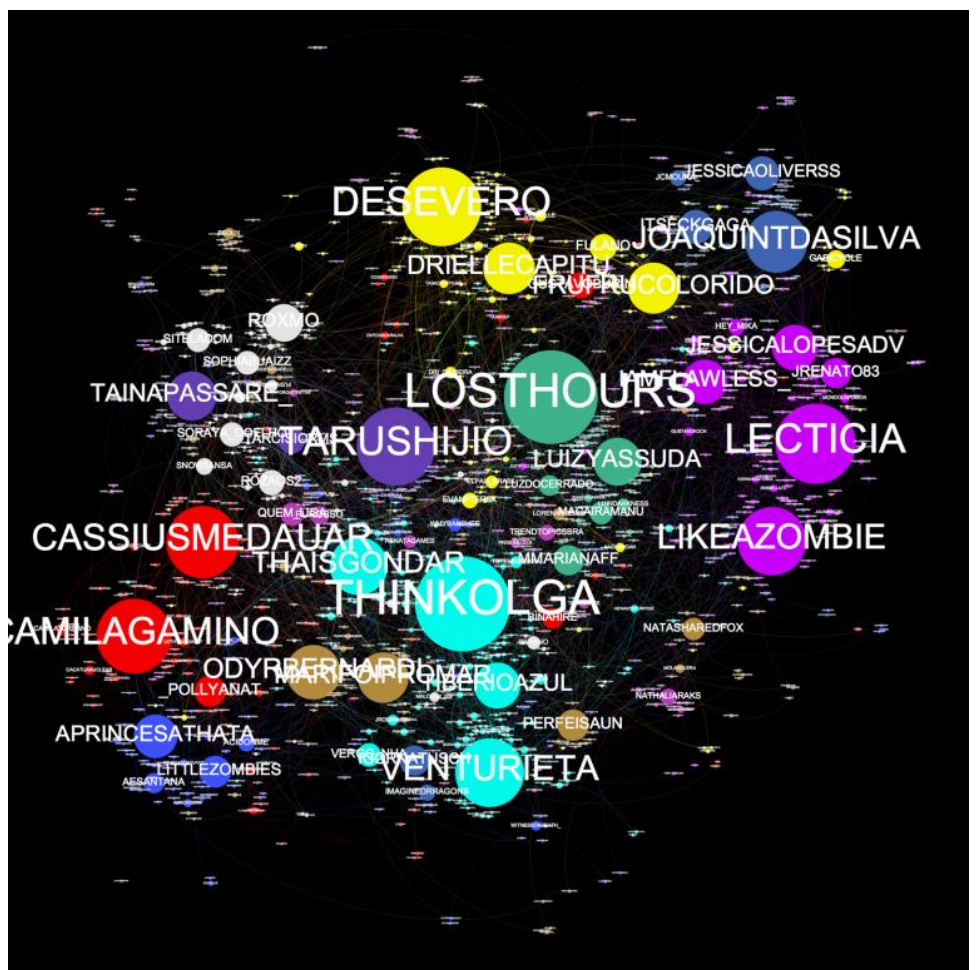

Fonte: As autoras (2015) 
Feminismo 2.0: A mobilização das mulheres no Brasil contra o assédio sexual através das mídias sociais (\#primeiroassedio)

Apêndice 2: Grafo 2 - Segundo momento da rede

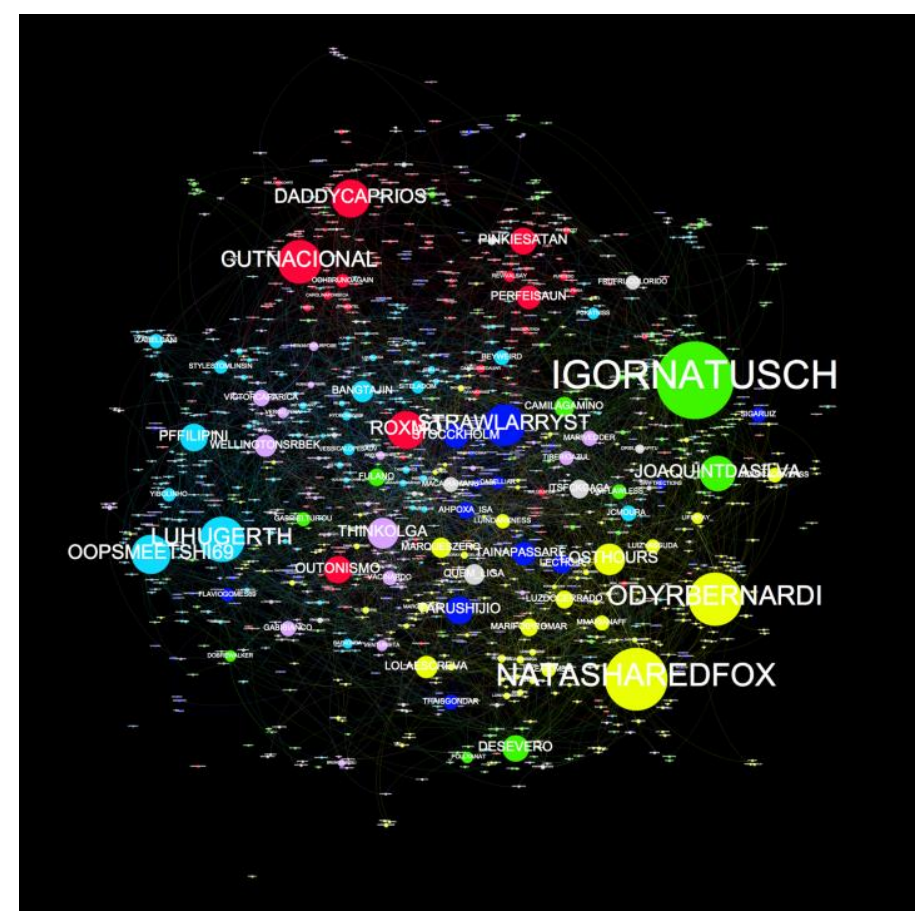

Fonte: As autoras (2015)

Apêndice 3: Grafo 3 - Terceiro momento da rede

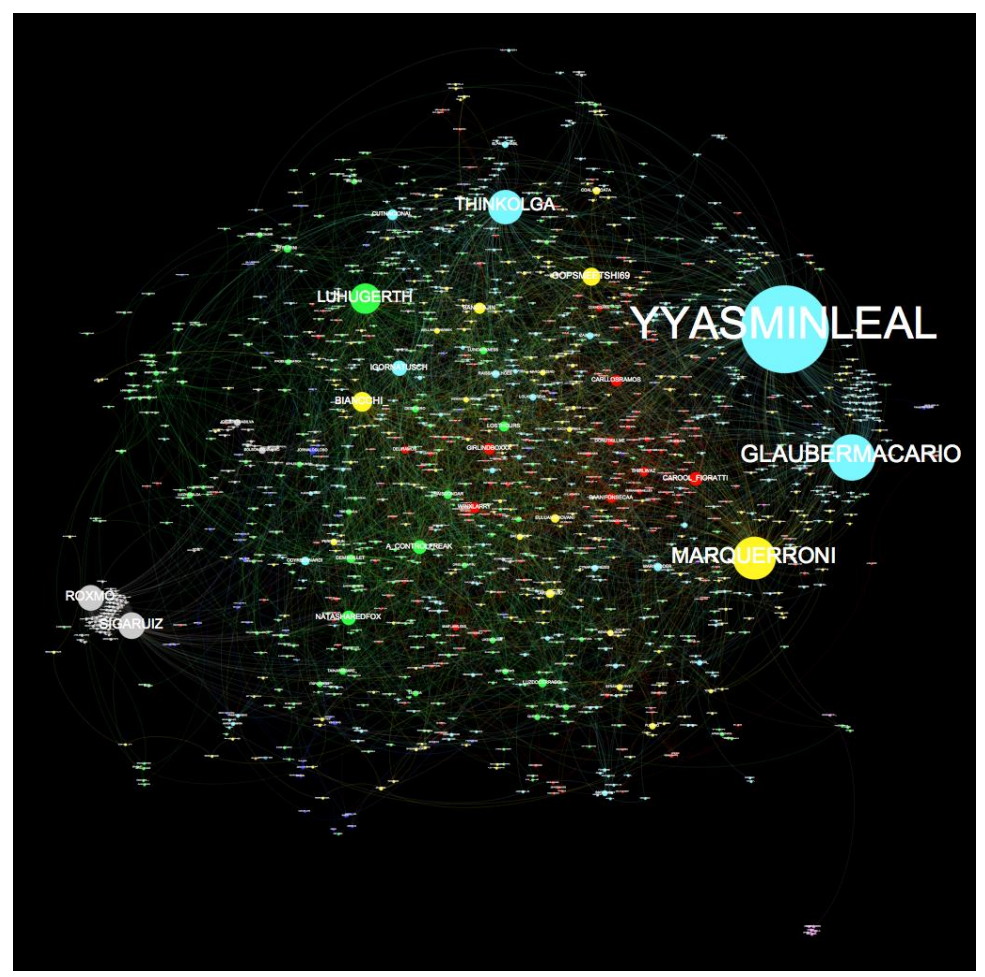

Fonte: As autoras (2015) 
Apêndice 4: Grafo 4 - Quarto momento da rede.

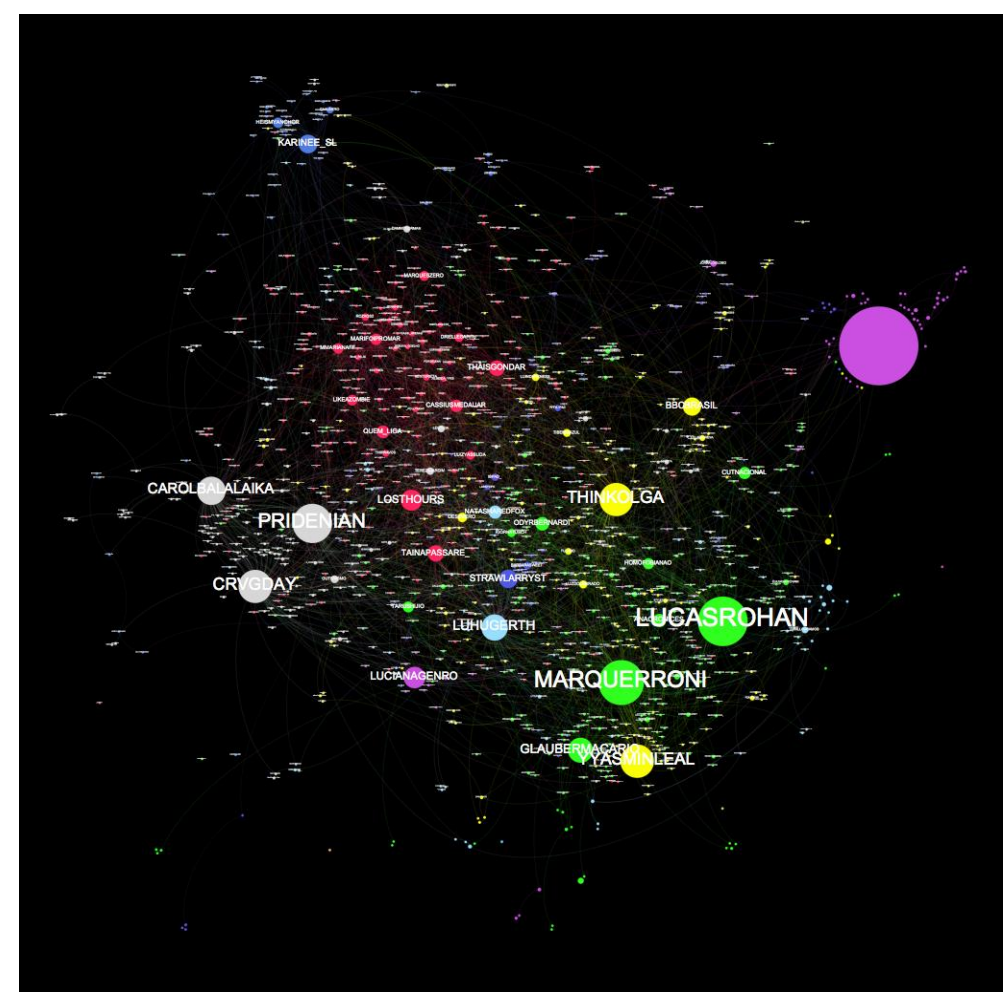

Fonte: As autoras (2015)

Apêndice 1: Grafo 5 - Quinto momento da rede

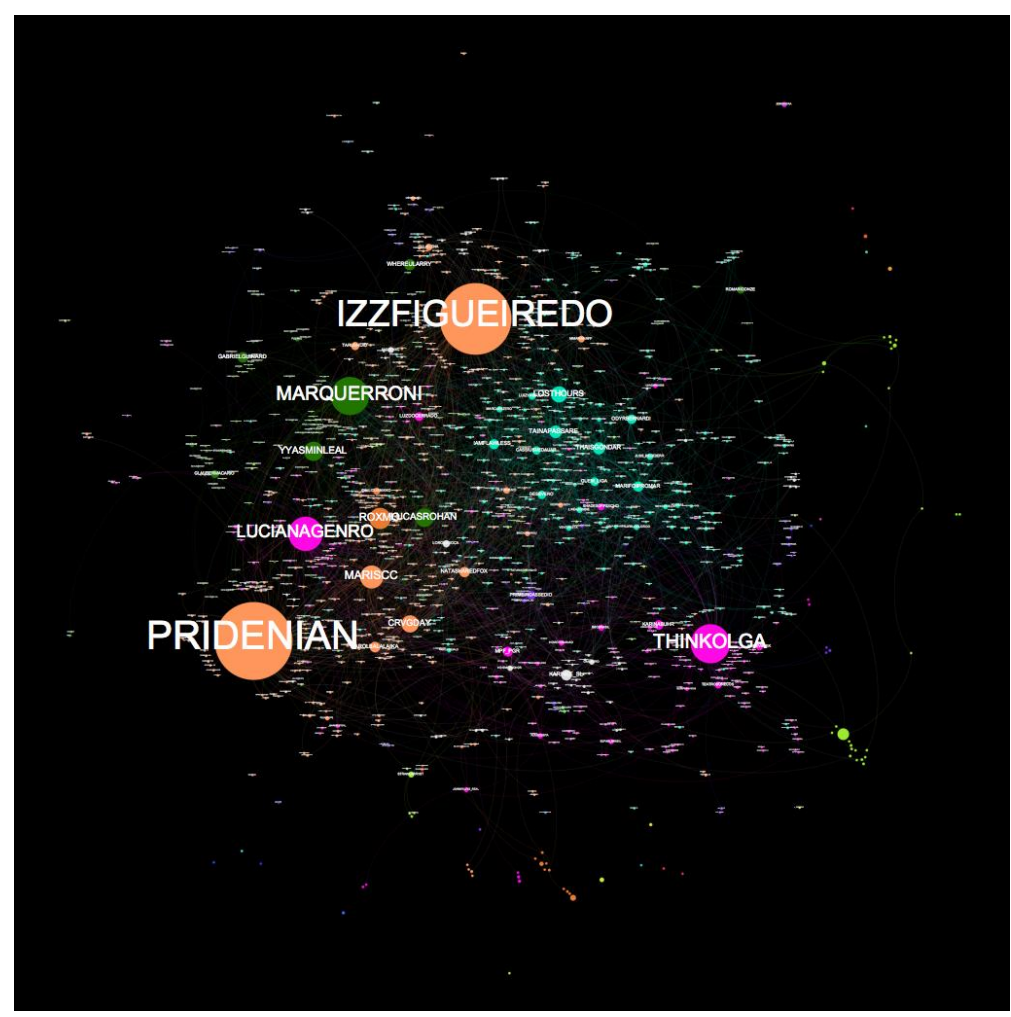

Fonte: As autoras (2015) 